\title{
Critical Incidents: Staging and process in crisis negotiations
}

\author{
Name: $\quad$ Dr. Terry D. Royce \\ Position: $\quad$ Senior Lecturer Research Literacies \\ Affiliation: Graduate Research School, University of Technology, Sydney (UTS). \\ City Campus, 15 Broadway, Ultimo, Sydney, Australia 2007 \\ Phone: $\quad$ 02-9514-2485 \\ Mobile: $\quad 0402627000$ \\ Email: $\quad$ terry.royce@uts.edu.au
}

\begin{abstract}
Much of the literature on using communication skills in negotiations in critical incidents tends to focus primarily on analyses at the word, clause, or sentence level (or micro level), and typically classifies, labels, and interprets these in terms of sets of active listening skills (mirroring, emotion labeling, paraphrasing, etc.), or suggested example phrases that negotiators need to draw upon for rapport-building during an incident. The analysis presented in this paper attempts to move away from this micro level focus by analysing the stages and processes of a critical incident from a macro or discourse view. It is proposed that an analysis of the ways that the interaction between the police negotiator and the person of interest (POI) moves through various stages, and cycles through various interactive processes, can be revealing in terms of the critical moments when these occur, and in explicating the ways that critical incidents can unfold.
\end{abstract}




\section{Critical Incidents: Staging and Process in Crisis Negotiations}

\section{Introduction}

Currently, many law enforcement agencies around the world recognise that negotiation, as opposed to a tactical response, is the principal tool to be used for peacefully resolving crisis situations. The FBI currently classifies crisis incidents into two main types: a hostage situation, where at least one person is held captive and used as leverage to fulfill substantive demands (for money, freedom, political change etc) and the primary law enforcement goal is not to harm the hostages, and a nonhostage situation, where "individuals act in an emotional, senseless, and often self-destructive way” (Noesner, 1999, p. 8), with actions stimulated by resentment, extreme anger, frustration, and depression. The negotiation processes involved in both these crisis situations necessarily vary in terms of the law enforcement strategies employed (see summary in Noesner 1999, p. 9), but both are characterised by attempts to use communication skills (focusing on active listening) to resolve the crisis. Much of the literature on using communication processes in negotiations in critical incidents tends to focus primarily on analyses at the word, clause, or sentence level (or micro level), and typically classifies, labels, and interprets these in terms of sets of active listening skills (mirroring, emotion labeling, paraphrasing, etc.), or suggested example phrases that negotiators need to draw upon for rapport-building during an incident (Wind, 1995; Noesner \& Webster, 1997; Lanceley, 1999; McMains \& Mullins, 2001)

The analysis presented in this paper attempts to move away from this micro level focus by analysing the stages and processes of a critical incident from a macro or discourse view. It is proposed that an analysis of the ways that the interaction between 
the police negotiator and the person of interest (POI) moves through various stages, and cycles through various processes, can be revealing in terms of the critical moments when these occur, and in explicating the ways that critical incidents can unfold. This is a text- or discourse-level approach used in forensic discourse analysis (derived from forensic linguistics) in which there is an assumption that all communication unfolds in stages, and the language choices the interactants make to realise these stages are motivated social purposes arising from the immediate and previous context(s). The particular incident being analysed here is one involving a negotiator for the New South Wales (NSW) Police Service, Australia who is tasked with serving a "high-risk warrant" on a perpetrator who is known to be armed, is expected to violently resist, and has demonstrated that he is a serious danger to other people (McMains \& Mullins, 2001, p. 39-40).

\section{The stages and processes in crisis negotiations}

In the same way that all communication, written or spoken, is viewed as moving through recognizable stages, so too can a critical incident be interpreted as unfolding in stages. Two approaches to staging in crisis negotiations, both of which approach it mainly from the point of view of the negotiator, are given below; the first is from a forensic psychology perspective, and the second a law enforcement and corrections context.

From a forensic psychology perspective, Call (2003; 2008, p. 280) interprets crisis negotiation in terms of five stages:

1. Intelligence gathering: develop strategy(s) to approach the crisis and deal with any potential problems. 
2. Introduction and relationship development: after contact is made take steps to build rapport and defer action on instrumental demands until rapport is evident.

3. Problem clarification and relationship development: with rapport established negotiate (bargain) 'normatively’ rather than using 'brinkmanship’.

4. Problem solving: based on the rapport, start to develop proposals to solve the situation and seek compliance.

5. Resolution: based on continuing rapport carefully organise steps for any hostage release, and an efficient and safe surrender.

The stages of a crisis are also explicated in a police training and correctional context by McMains and Mullins (2001, p. 68-76), who suggest that this can be characterised as going through four distinct stages:

1. Pre-crisis: those involved in a potential crisis perform normal daily activities.

2. Crisis/Defusing: something triggers intense emotional excitation in the subject, unpredictability and uncertainty increases, and he/she chooses a course of action which leads to police involvement and their initial attempts to defuse the crisis.

3. Accommodation/Negotiation: the subject involved is beginning to be open to suggestions, emotional excitation decreases, and rational thinking increases (often with instrumental purposes).

4. Resolution/Surrender: the subject can start to see answers and a clear path to an alternative solution, agrees with and tries new ideas, and makes moves towards a conclusion. 
While McMains and Mullins (2001) acknowledge that there are other views or interpretations of the stages a crisis may go through (depending on the analyst's perspective), they do emphasise that a crisis should be viewed as a process, with "predictable stages through which people move [and that] each stage has different issues with which negotiators must deal and requires different skills that are valuable in dealing with the issues of that particular stage” (McMains \& Mullins, 2001, p. 68). Their view of the process is clearly a more interactive, process-based view, which does to an extent, take into account the fact that the stages unfold as the interlocutors involved draw upon various interactive processes.

Rogan, Hammer, and Van Zandt (1997), in their review of negotiation models in crisis situations, posit that there are two main approaches to crisis negotiation. These have been categorised as the instrumental approach and expressive acts approach, a categorization that has basically served as a "general template through which negotiators determine the type of crisis negotiation situation they are facing and the subsequent strategies employed for obtaining a resolution” (Rogan, Hammer, \& Van Zandt, 1997, p. 9).

The first of these approaches, the instrumental or bargaining approach, “conceptualises crisis negotiations in terms of instrumental issues present during negotiation". These relate to "those situationally related, substantive, objective wants or demands of each party......'whereby' negotiation is viewed in terms of efforts by each party to dictate or clarify the terms of an exchange or distribution of resources” (Rogan, Hammer, \& Van Zandt, 1997, p. 10). Further, this approach to negotiation "posits a rational actor model of negotiation which characterises effective negotiation 
as the result of rational discourse between contending parties [i.e. where each party focuses on instrumental, substantive issues and makes logical cost/benefit choices]” (Rogan, Hammer, \& Van Zandt, 1997, p. 10).

The orientation of the behaviors of the negotiators in this 'bargaining' approach is thus towards some kind of substantive instrumental outcome, and it essentially views negotiation as "agreement-making through bargaining or problem-solving, typically via quid pro quo" (1997, p. 11). This instrumental approach has also been extensively drawn upon and applied in other contexts (labor/management disputes, for example), but there are problems with its use for crisis negotiations as these are often characterised by high levels of anxiety, emotion, apprehension, and uncertainty for both parties, making the assumption of rationality and a willingness to bargain often impossible to maintain (1997, pp. 10-11). Additionally, many incidents actually involve critical issues to do with aspects of relationship and face, in combination with the various elements of instrumental behavior, so an assumption that objective bargaining alone is sufficient may be too narrow an approach to characterise negotiation processes (1997, p. 12).

As a result of this, the expressive negotiation approach has been proposed as a alternative way for characterising the ways to resolve crisis situations. In this approach, it is presumed that "the nature and quality of interpersonal relationships plays a large role in resolving conflict” (Rogan, Hammer, \& Van Zandt, 1997, p. 12; see also Schlossberg, 1979; and Fuselier, 1999 on negotiation and the Stockholm Syndrome). This approach contrasts with the instrumental approach in that it views emotion and relationship variables as the key elements, and sees relationship 
development via rapport and trust-building as crucial. A very common recommendation given in negotiator training is thus to emphasise 'active' "listening, paraphrasing, self-disclosure, open-ended questioning, and specific skills for reducing the perpetrator’s anxiety level” (Rogan, Hammer, \& Van Zandt, 1997, p. 13).

Rogan, Hammer, and Van Zandt (1997), further posit that while the instrumental and expressive approaches have been clearly of great benefit to developing an understanding of negotiation dynamics, these approaches have been largely one-sided, focusing mainly on perpetrator behavior, or on his/her emotional and mental state. They argue that what is more appropriate is a communication-based or interactive approach, where crisis negotiation should be focusing on both perpetrator and negotiator behavior as revealed by their verbal messages. This interactive perspective takes into account the fact that a crisis situation is a developing one that is actually cocreated by the interactants as they exchange messages with each other.

Rogan, Hammer, and Van Zandt (1997) outline their communication approach by suggesting that all communication, in line with basic communication theory, has both a content and relational dimension. The former relates to the instrumental focus of communication, while the latter refers to its expressive features (which is further broken down into relational and identity information). They further posit that "parties to conflict interaction pursue three functional interactional concerns which impact on conflict escalation/de-escalation - these are instrumental, relational, and identity or face goals” (Rogan, Hammer, \& Van Zandt, 1997, p. 14-15). Their aim is thus to develop a model of negotiation that takes into account the already-mentioned 
instrumental and expressive aspects of negotiation processes, and to interpret these in a negotiation interactively as the negotiation unfolds.

While these instrumental, expressive, and interactive approaches to negotiation have been very helpful in characterizing negotiation processes and staging, there should also be some consideration as to how context plays a role in the unfolding of a crisis, and the ways that a negotiation may unfold. Thus,

negotiation may progress in a stage fashion, moving from crisis bargaining toward normative bargaining via phases, or negotiation progress may be interdependent with integrative and distributive bargaining intertwined. However, the negotiation may also remain fixed and separate, with the perpetrator remaining in crisis bargaining mode while the negotiator attempts to bargain normatively (Call, 2003, p. 85).

Further, the issue of how a negotiation 'success' can be defined is also important, as not all negotiations end with the surrender of the perpetrator (or the release of any hostages). As Call (2003, p. 85) further points out, "no longer does a tactical solution equate with a negotiation failure. Rather, negotiating success is judged by stabilizing the incident through 'verbal containment'”.

\section{A discourse or macro view of critical incident interaction}

It is important to note at this point that these views of crisis negotiation staging, as well as the instrumental, expressive, and interactive approaches, are broad-spectrum categorisations which can usefully describe general interactional orientations. It is also important to note that the end-products which give rise to these characterisations 
of negotiation are realised by the type and nature of the individual exchanges as they unfold between the interactants.

As they interact, the people involved in a crisis negotiation make language choices which work to realise the purposes they want to enact (whether they be instrumental, emotive, or relational in focus). Rogan, Hammer, and Van Zandt's (1997) generalisation that all communication has both a content and relational dimension can be more deeply expounded by drawing upon functional linguistic insights in relation to speech, meaning and context in communication (Halliday, 1994). In this functional view, when two (or more) people interact they not only deal with certain subject matter, topics or experiences relevant to the context in which they are situated (or ideational meanings), they also establish relationships between themselves: between the person who is speaking at a particular moment, and between the person who will probably speak next (or interpersonal meanings). In producing these content-based meanings with another person or people, the interactants are also able to vary the channels via which they choose to communicate, as well as how they sequence the ideas and information they are exchanging (or textual meanings) (Halliday, 1994).

Models of spoken discourse analysis such as Conversation Analysis (Psathis, 1995) also support this view: to establish relationships and to deal with subject matter we take interactional turns, and in those turns we take on different speech roles to exchange meanings (and therefore positions of power). The basic speech roles are giving and demanding (Halliday, 1994) and these generate other speech function pairings such as statement-acknowledgement, question-answer, commandcompliance, offer-acceptance etc. Depending on the role taken up by a speaker, 
information is bandied back and forth between the interlocutors, and the dialogic exchange moves through what can be characterised as moves or interactional processes, with a shifting of speech roles and established positions of power (such as initiator, responder etc). Spoken interaction thus involves the dynamic process of building some kind of relationship between the speakers, and in moving through various processes, processes which can be described to various levels of delicacy (or in micro and macro terms).

\section{The case study}

The concept of interactional processes, as suggested above, will be drawn upon in analysing exchange between the police negotiator and the POI in this particular critical incident. It is proposed that as the interactants move through the various stages of the crisis, they also move in and out of various interactive processes, depending on what stage they are at, and depending on their interactional purposes at each stage. It is also suggested that this cycling in and cycling out will change in nature and perhaps intensity as the interaction moves into its final stages, where there is finally some kind of resolution.

\section{Data and method}

The data which is the subject of this analysis of staging and process was obtained from the personal tape recordings by the NSW Police negotiator involved in this crisis incident, Detective Inspector (now Detective Superintendant) John O’Reilly, then Metropolitan Team Leader of the NSW Police Service Negotiation Team of the NSW Police Service. Additional supportive data sources were two video tapes related to the incident - one a surveillance video of the property and the POI by the tactical team, detailing the subject's perimeter defences and habitual personal actions, the other a 
video with audio of the entire incident from containment to arrest. Important background and contextual information was obtained from the negotiator's personal tape recordings of an interview the negotiation team and bomb squad held with an informant, as well as informal interviews and correspondence with the negotiator, where both general and specific information relating to the incident were obtained.

The tape-recorded text was transcribed and the exchange between the POI and O’Reilly has been analyzed in terms of:

1. The pre-incident context: the important background details of the intelligence gathered on the POI prior to the crisis, and details about the tactical setup (extracted from a tape-recorded interview and police video).

2. The initial stages of the POI text: an analysis of how the POI is isolated and contained, and the moves made towards establishing rapport and defusing the crisis. This involves a brief analysis of where and why O’Reilly uses active listening skills and the effect on the interaction as it develops.

3. The subsequent and final stages where the interaction unfolds towards resolution and surrender via cycles of instrumental and expressive processes.

\section{Text Analysis: The stages and interactive processes of the crisis}

The whole exchange between O’Reilly and the POI from initiation to arrest, lasts for around 47 minutes. The analysis and characterisation of the stages will be informed by elements of the model suggested by McMains and Mullins (2001), and due to the incident's atypical nature (in terms of the role and use of prior contextual knowledge), elements of Call’s (2003, 2008) perspective on staging from forensic psychology will be drawn upon and adapted (specifically the intelligence gathering 
stage). A full summative analysis of the stages and processes, the purposes associated with each, and sample utterances are given in Table Two at the end of this discussion.

\section{Stage One: The pre-crisis context}

The POI lives on his own farm in rural NSW and is alleged to be regularly entering a nearby town carrying loaded weapons and wearing an IED (Improvised Explosive Device), ostensibly for his own protection against perceived threats by the townspeople. The critical incident analysed here fits into a "nonhostage situation" classification (Noesner, 1999), and as such involves an interaction with an expressive subject. There is however one important difference from the situation which would typically face a police negotiator called out to deal with a critical incident - this is extensive access to and use of advance intelligence provided by the tactical, bomb disposal, and negotiator team members, and then used to effect in the unfolding stages of the actual negotiation. O’Reilly and his fellow team members also have access to the information provided via an interview with an informant. The details gleaned from this interview and other advance intelligence are summarised in Table One. This shows that the police negotiation teams must necessarily view the POI as a potentially very dangerous person who has very negative attitudes towards society and authority. The teams are also aware of the potential danger to others, in that the POI has been wearing a 'hot' IED, and carrying concealed weapons to the nearby town for at least four months. 


\section{Table One: Informant interview results}

\begin{tabular}{|c|c|}
\hline Personality traits & $\begin{array}{l}\text { Secretive, explosive temper. Paranoia - feels protected and in command when } \\
\text { wearing IED in town - always wears it in town - feels it is better protection } \\
\text { in town than just handguns. Admires 'Rambo'. Limited conversational } \\
\text { abilities. Likes to feel that he is in control or has power. }\end{array}$ \\
\hline Belief systems & $\begin{array}{l}\text { No religious affiliations or beliefs in organised religion. Machines come } \\
\text { before people. His pets come before people. Human life has no value. }\end{array}$ \\
\hline Interests and skills & $\begin{array}{l}\text { Mechanical aptitude and has respect for machines. Pilots licence. Significant } \\
\text { knowledge of and background with weapons. Able to build own } \\
\text { firearms/cannon and to construct a pressure-switched IED. Strong interest in } \\
\text { Thailand where he feels he can do anything he wants [money and } \\
\text { prostitution]. }\end{array}$ \\
\hline Family relations & $\begin{array}{l}\text { Estranged - did not attend mother's funeral. No contact with father. Other } \\
\text { family members seen very occasionally. His guns and dogs come before } \\
\text { family. }\end{array}$ \\
\hline Reaction to authority & $\begin{array}{l}\text { Government are 'thugs' manipulate everyone (telephones, banks, TV, police } \\
\text { etc.). Hates local council - they should be shot. No trust in doctors - self } \\
\text { medicates. }\end{array}$ \\
\hline Feelings towards others & $\begin{array}{l}\text { Weapons are more valuable than people. Misogynist. Humans are } \\
\text { 'domestics', 'two legs' or 'functionoids'. The local townspeople should be } \\
\text { shot and used for fertiliser. No friends except 'Old Nazi' in Thailand. }\end{array}$ \\
\hline Living circumstances & $\begin{array}{l}\text { Lives in caravan on own property. Largely self- sufficient existence - buys } \\
\text { supplies in town occasionally. Caravan is booby-trapped when he is away. } \\
\text { Has made land mines ready to plant on property away from access track. }\end{array}$ \\
\hline Possessions & $\begin{array}{l}\text { Keeps antique pistols/guns, 1-inch cannon, stockpile of weapons and } \\
\text { ammunition. Owns and uses forge, lathe and machine tools. }\end{array}$ \\
\hline Habitual actions & $\begin{array}{l}\text { No history of actual violence. Used to wear two IEDs and carried two } \\
\text { handguns in town. Now carries one more powerful body IED and three } \\
\text { handguns. Has been wearing a 'hot' pressure-switched IED to town for about } \\
\text { four months. Uses motorised bike to leave property along sandy access track }\end{array}$ \\
\hline
\end{tabular}

On the day of the incident, the site was set up for maximum protection of the police involved, due to the possibility that the IED would be detonated. Basically, the POI was intercepted on the crest of an access road which had been chosen as a result of the covert surveillance of the property and his movements in the weeks prior to the incident. The access road was sided by bushland which was enhanced for police safety by a series of protective layers: wire strung between knee high star pickets, a string of waist high detonator cord, rolls of razor tape, and a cyclone wire fence almost two metres high. This crisis incident is therefore somewhat atypical in the 
sense that the police have set up these protective measures in advance of the actual crisis. These kinds of actions might well be done in response to a crisis with the same elements, but here, in the interests of public safety, the police have prepared for and then initiated the crisis.

\section{Stage Two: Crisis}

The containment and isolation features involved in the crisis stage are concerned primarily with establishing legal and behavioral boundaries via a megaphone warning to stop and stay within the defined boundaries (the dirt access road). This is a pivotal point, for if the POI had not complied with the megaphone warning to stop and dismount, and had attempted to leave the "road-kill [zone]", a tactical response (by police snipers) would have resulted.

The actual crisis is initiated by the POI being addressed by O'Reilly through megaphone ("POI, You are under arrest”). O’Reilly addresses the POI with a preprepared statement via remote megaphone from the crisis response command post, with supporting officers in the command post, and a field observer. The POI is on a motorised bicycle on a narrow farm access road, and is surrounded (boxed in) by police snipers in foxholes, and the road is blocked by a Saracen (armoured personnel carrier). The POI is surprised and then contained by the pre-arranged sequence of utterances aimed at stopping and controlling his forward movement ("Stop immediately, and stay exactly where you are"), warnings about the danger of non-compliance (“... armed police, who will be forced to defend themselves...”), showing that the police are aware of his 'power' ("they know that you are armed, that you are wearing a bomb"), and instructing him regarding the next steps to take ("pick up the phone"). After the POI 
has been halted, a further two minutes of these kinds of warnings and instructions follow until he demounts his pushbike and picks up the phone on the side of the road.

This containment refers not only to physical containment, but also to psychological (communicational) containment (Cambria et al., 2002, p. 339). In this situation the POI is compelled to talk to O'Reilly only (thus the isolation), and there would be no use of third party intermediaries (Romano, 1998, p. 20).

\section{Stage Three: Crisis/defusing}

Once the POI is contained and isolated, O'Reilly switches from the megaphone to the actual negotiation by phone, and thus initiates the crisis/defusing stage of the negotiation. This is a move into the expressive stage of the negotiation, where he attempts via active listening to establish a relationship with the POI in order to convince him to comply with the request to defuse/remove the IED, and to surrender the firearms and ammunition.

The initial purposes in these processes are to establish who the participants in the interaction are via a 'greeting and identification' exchange. This clearly lets the POI know who he is talking to (negotiator's name) and to which side he belongs (the police). What follows next in this crisis-defusing stage are a series of expressive processes aimed at explaining why the situation has arisen ("We know you've been going into town with a bomb and there's a lot of people very worried about that."), building rapport via active listening (see discussion below), and an attempt to move the POI into more rational instrumental (bargaining) processes. 
As already mentioned, the use of active listening by negotiators is a basic feature of the expressive negotiation approach, an approach which emphasises the importance of the nature and quality of interpersonal relationships formed in attempting to resolve a crisis (although it is of use in the other stages of a crisis negotiation since the relationship has to be maintained). The interactional linguistic choices made by a negotiator, in response to the language choices of the perpetrator, are therefore obviously of prime importance in this process, and the unfolding exchange between O’Reilly and the POI, and the instances where O’Reilly draws upon active listening skills to establish rapport to defuse a potentially volatile situation demonstrate this. Royce (2005), in a discussion and analysis of active listening in this incident, found that O'Reilly draws upon the following common active listening skills: 'I' messages (including shifts from first, to second to third person pronoun usage in order to set himself up as a third party who can help the POI); mirroring; paraphrasing; tag questions and eliciting statements; open-ended questions; minimal encouragements; and effective pauses.

O’Reilly also draws upon an interactional technique which has not been covered in the literature on active listening in crisis situations, which Royce (2005, pp. 22-23) has referred to as "reflective empathisers", instances of which can be seen in these typical examples: "I understand what you mean ...; I know what you're saying ...; I know that, I know that ...; I know from your perspective it may seem ridiculous ...”). These do not reflect back the propositional content of the POI's utterances through repetition or synonymising (which is what mirroring basically does), but ellipse the meanings expressed and work to maintain the interactional exchange. 
There is also a critical moment where the transition into the next stage of the negotiation occurs, where O'Reilly begins to assume the role of 'rescuer', but where the POI's developing realization that he is boxed in by the police leads to some agitation. At this point O’Reilly cuts him off (“just listen to me for a moment please POI ....”), but continues to refer to 'the police' and 'them' in order to maintain the sense of separation, and the idea that it is these "others' who are constraining the POI, not O’Reilly. His follow-up reference to the 'Saracen’ (“If you look down the road you'll see a Saracen") is further confirmation of the control the police have over the POI; it is also a deliberate choice of words based on the prior intelligence, because O’Reilly knows that the POI would be impressed by this military machine (“This is amazing”), and the tactics used (O’Reilly, 2003).

\section{Stage Four: Accommodation/negotiation}

At this point the POI knows that he has been isolated and constrained, and this critical turning point, where he capitulates and starts to allocate decision-making and advising power to O’Reilly, is realised by his next utterances which ask: ("Rightio, well what are you going to do? '.....' Then what do you intend to do?). This choice of words and their interrogative focus move the interaction into the accommodation/negotiation stage. Once this move has been made, the POI begins to signal an openness to suggestions, experiences less emotional excitation, and becomes more concerned with bargaining over substantive issues.

This is a very important interactional stage for the POI and O’Reilly, because they are now "in this together” (Cambria et al., 2002, p. 339), and it represents the start of the process of disarming the IED and the removal of the weapons. This attitudinal 
change and the resultant move into the accommodation/negotiation stage is further reinforced very quickly where the POI removes his helmet, a physical act designed to facilitate ease of communication, and says "hold on till I get my helmet off, its so bloody hot here”. This desire to continue the interaction in a more comfortable way suggests that O'Reilly has, in effect, become the 'rescuer' of the POI, though not totally, because the POI (after previously foreshadowing this in the last exchanges in the crisis/defusing stage) raises substantive issues concerning himself and his possessions.

What follows this assigning of agency to O’Reilly are a series of cycled (ebb and flow) exchanges dealing with such substantive issues as: future actions ("Well this means I've finished with this bloody country then '....' Well what do you intend to do with me then, I mean will I be able to come back and get my things on the way and sell things or ...?”); his possessions (“weapons '....' sell my land '....' my bike ‘...' pistols '....' cash"); and perceptions of his behaviour ("what I've got [the IED] is absolutely safe '....' I was worried you were attacking me”).

Throughout the rest of the exchange in this stage the POI cycles through these issues, sometimes two to three times, seeking assurances from O'Reilly before he accommodates and moves on to the next requested action. These exchanges are steps in an unfolding process of cycling (bargaining) moves that start with raising the issue, then settling or receiving assurances, accepting, and then completing the action.

Each cycle in this bargaining process is associated with accommodation processes where the POI complies with O'Reilly's requests, and the ending of each cycle in a 
sense acts as an initiator for the next round of (bargaining) processes, thus moving the negotiation step-by-step along to its resolution. The main accommodation processes are concerned with direct agreement to carry out or comply with requested actions, either through statements of agreement (“OK. I'll leave my things here on the road '...' '), or via helpful interrogative suggestions ("Do you want me to take my socks off too, yes?”). These are associated with multiple requests for guarantees or promises in relation to the substantive issues, actions, procedures and possessions ("But you're giving me a guarantee that I can definitely get out of this country?”), and clarifications of communication where there are requests and/or agreements to make the communications as smooth as possible ("Wait on, I won't be able to talk to you with it [the helmet] off, yes I can, rightio. '.....' All right, wait a minute, OK, rightio”).

Based on this established rapport the POI in the end has agreed to completely remove all his clothes, and to remove, defuse, and disassemble the IED and lay its components on the ground in a neat row. The weapons and the ammunition have also been removed and rendered safe, and all other personal items have been laid out on the ground in a neat fashion. The POI has been assured that these items will be returned to him, subject to legal proceedings. The POI now trusts O’Reilly and he in turn receives assurances regarding his treatment with dignity as he disrobes, the legal processes involved in his charges, and the steps he can take with his possessions, the sale of his land, and his eventual departure from Australia.

\section{Stage Five: Resolution/surrender}

The move to the resolution/surrender stage follows quickly once the cycling of these bargaining issues is settled and accommodations made. There are still, however, 
processes in this stage which move the interactions along to the point where the POI is finally taken into custody. These are all expressive in nature, not only because the substantive issues have already been covered, but because this is the point where the rapport is the strongest. Evidence of these kinds of expressive, affirming processes are seen in the accommodating requests for clarification the POI makes to ensure he is doing the right thing and satisfying the thrust of O’Reilly's instructions ("POI: Rightio, so I just keep walking towards them? OR: Just keep walking towards them '.....' POI: This is wonderful '.....”’). It is also seen in the final rapport confirmation processes where they exchange names in a much more friendly way than the opening arrest exchanges (“POI: So John what? OR: John O'Reilly. POI: O'Reilly, rightio, ‘.....' names, $\left.O K^{\prime \prime}\right)$. The final interactive process is for closing, where communication is broken off and the arrest effected (“OR: Thank you 'POI’. POI: Rightio, bye.”). 
Table Two: Staging, process and purpose

\begin{tabular}{|c|c|c|c|}
\hline STAGES & PROCESSES & PURPOSES & EXEMPLARS: EXCHANGES AND INSTANCES \\
\hline PRE-CRISIS & $\begin{array}{l}\text { INTELLIGENCE- } \\
\text { GATHERING }\end{array}$ & Setting (up) the scene & $\begin{array}{ll}\text { - } & \text { Incidents in town (visiting town, bank, police station wearing armed body IED and guns). } \\
\text { - } & \text { Police interview (with person who knows POI) } \\
\text { Police intel on property (carrying guns while patrolling perimeters; general paranoid behaviours) }\end{array}$ \\
\hline CRISIS & $\begin{array}{l}\text { CONTAINMENT } \\
\qquad \& \\
\text { ISOLATION }\end{array}$ & $\begin{array}{c}\text { Stating situation \& } \\
\text { effect }\end{array}$ & $\begin{array}{l}\text { O: "POI" You are under arrest. Stop immediately, and stay exactly where you are ....., There are police all around } \\
\text { you, ...... You will be safe if you stay exactly where you are, and do exactly as I ask. Stop where you are now ..... If } \\
\text { you do as I ask, I can guarantee that you will be safe...... If you attempt to move away from the spot in which you are } \\
\text { standing, you will be approaching armed police, who will be forced to defend themselves..... Walk over to the witch's hat, } \\
\text { and pick up the phone. ..... There are armed police all around you, you cannot leave that spot. You are safe while you } \\
\text { stay there - do not leave that spot. }\end{array}$ \\
\hline \multirow{4}{*}{ CRISIS-DEFUSING } & \multirow{4}{*}{ EXPRESSIVE } & $\begin{array}{l}\text { Greeting } \\
\text { Identification }\end{array}$ & $\begin{array}{l}\text { O: Hello, “POI”. } \\
\text { P: Who's this? } \\
\text { O: Yes, my name's John, “POI”. I'm a police negotiator. } \\
\text { P: Oh, yeah...... }\end{array}$ \\
\hline & & Explaining & $\begin{array}{l}\text { O: We know you've been going into town with a bomb and there's a lot of people very worried about that. OK That's why } \\
\text { we're here, because we know you've got guns and we know that you've got a bomb. } \\
\text { P: Well that's only if I was attacked...... }\end{array}$ \\
\hline & & Rapport-building & $\begin{array}{l}\text { O: I understand what you mean, but no-one wanted to attack you, no-one wants to go near you, they're frightened, } \\
\text { very worried about the bomb. You can understand that, can't you?...... } \\
\text { P: Now listen, this is absolutely bloody ridiculous. } \\
\text { O: I know from your perspective it may seem ridiculous, but the people in town are very worried about it and the police are } \\
\text { obligated to act, as you can understand. }\end{array}$ \\
\hline & & $\begin{array}{l}\text { Initial bargaining } \\
\text { (probing } 1^{\text {st }} \text { claim) }\end{array}$ & $\begin{array}{l}\text { P: Well certainly I'm going to keep my weapons, I've had them for most of my life. } \\
\text { O: I know that, I know that, but police have to make sure that the bomb is disarmed. }\end{array}$ \\
\hline \multirow[b]{2}{*}{ NEGOTIATION } & & \multirow[t]{2}{*}{ Actions (intended) } & $\begin{array}{l}\text { P: Rightio, well what are you going to do? } \\
\text { O: Well I need you to take off your overalls and take off the bomb and put it down on the road. } \\
\text { P: Then what do you intend to do? ..... Well this means I've finished with this bloody country then..... Now you want me } \\
\text { to, what do you intend to do with my weapons? ..... } \\
\text { P: Well what do you intend to do with me then, I mean will I be able to come back and get my things on the way and sell } \\
\text { things or ...? } \\
\text { O: Look.... it will be up to the court what happens there about the weapons and the bomb and everything, but ultimately } \\
\text { the land is yours and you can go back to it, there's no problem there...... }\end{array}$ \\
\hline & & & $\begin{array}{l}\text { P: Well what about my property and everything? ......... what do you intend to do with my weapons? ...... After I sell my } \\
\text { land, will I be able to get my weapons back and take them away with me? ...... Will I lose my bike then? ..... Um, well I }\end{array}$ \\
\hline
\end{tabular}




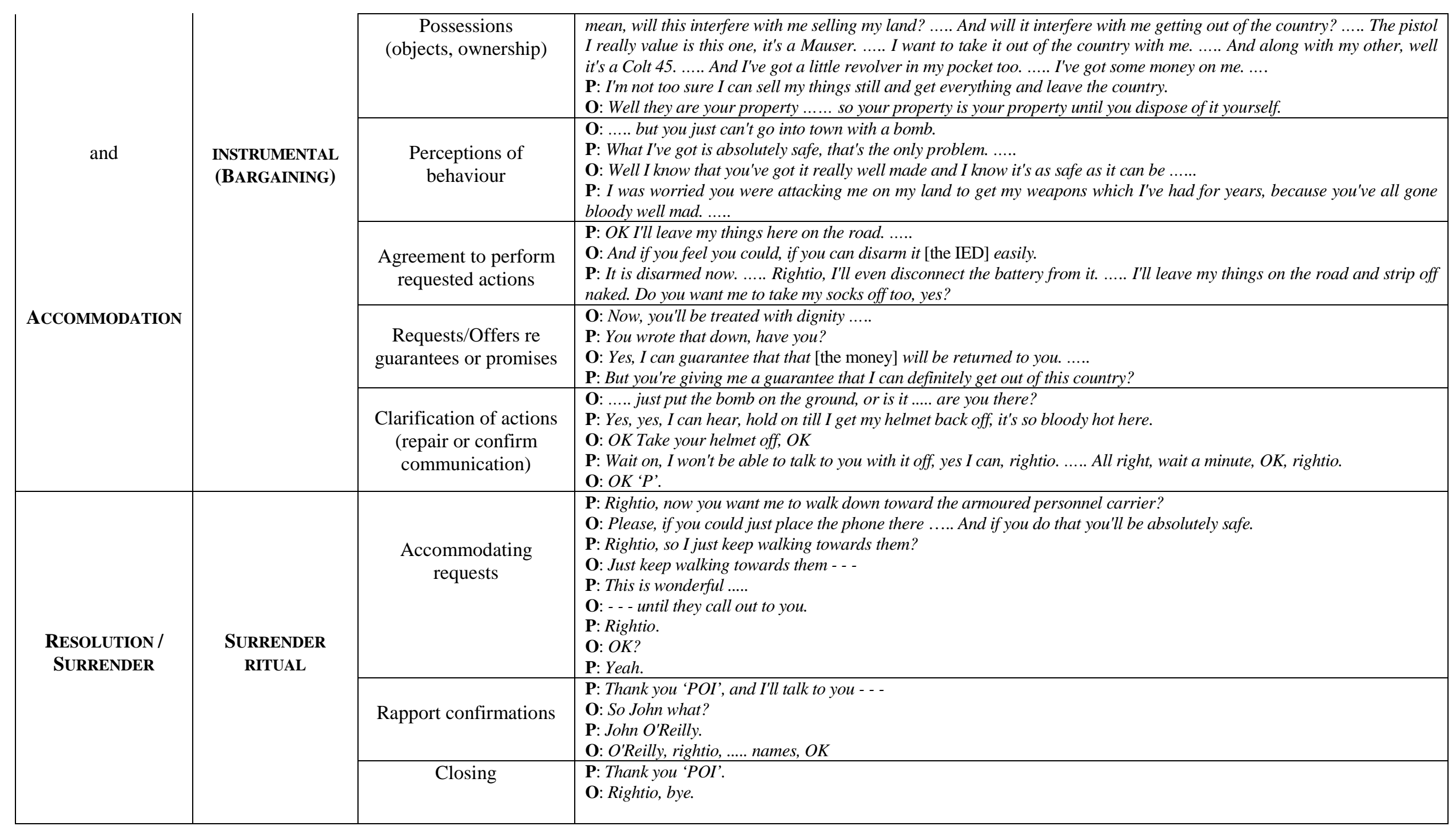




\section{Conclusions}

The analysis of the staging of this critical incident is well-informed by the stages as suggested by McMains and Mullins (2001) and Call (2003; 2008, p. 280), but with variations which may be peculiar to this incident, given the access to a lot of prior intelligence by the NSW police, and the fact that they actually initiated the crisis by laying in wait for the POI and executing a well-coordinated negotiation and tactical plan. As Table Two shows, there were five (not four) stages; the extra stage is the containment and isolation stage which has been termed 'crisis', and the preceding stage referred to as 'Pre-crisis' is characterised by the police gathering and utilising prior intelligence to set the scene for the crisis. Of course it is possible to break up these major stages into more sub-stages, increasing the level of delicacy in the analysis. For example, in the 'Purposes' column of Table Two, the purpose-based descriptors could well be used to describe the various sub-stages within each of the major stages.

In terms of the processes and their associated purposes, the linguistic choices made by O’Reilly in his initial interaction with the POI, the effective use of active listening techniques to establish an initial rapport with him in the crisis/defusing stage, and the cycling of instrumental and expressive processes in the negotiation and accommodation stage, have been important in the move into the final successful stage of resolution and surrender. O’Reilly was able to effect a disassociation from the 'police' and to build rapport as the interaction developed via his adaptive use of personal referential pronominals. He was also able to give the POI the impression that he was empathetic through a judicious use of reflective empathisers, which was supported by other active 
listening techniques such as mirroring, and paraphrasing (Royce, 2005). As empathy developed, and the POI began to see a way out of his predicament, O'Reilly was able to bring in the "voice of reason" to start to move the interaction towards the resolution/surrender stage (O’Reilly, 2003).

This analysis suggests areas for further interactional study of this kind of incident. One important area would be a deeper analysis of how the use of contextual knowledge influenced O'Reilly's language choices, thus providing another deeper angle on the ways that the stages of these interactions can unfold. This kind of analysis would be appropriate whether the contextual information was obtained in advance, or as the interaction proceeds via the usual note-taking and team data feeds to the negotiator as he/she speaks to a POI. One other interesting area would be an intonational analysis of vocal recordings of these kinds of interactions, especially in the move from a public megaphone to the more 'intimate' police phone. This could be correlated with the stages and functional moves occurring as an interaction unfolds.

\section{Acknowledgment:}

I wish to thank Detective Superintendent John O’Reilly, Commander, Operations Group, Counter Terrorist \& Special Tactics Command, NSW Police Force, for his cooperation, assistance and advice in the preparation of this paper, and the invaluable data upon which the analyses are based. 


\section{References}

Call, J. A. (2003). The evolution of hostage/barricade crisis negotiation. In Harold V. Hall. Terrorism: Strategies for Intervention, (pp. 69-94). New York: Haworth Press.

Call, J. A. (2008). Psychological consultation in hostage/barricade crisis negotiation. In Harold V. Hall. Forensic Psychology and Neuropsychology for Criminal and Civil Cases. (pp. 263-288). Boca Raton FL: CRC Press, Taylor \& Francis Group.

Cambria, J., \& R. J. DeFilippo, R. J. Louden, H. McGowan. (2002). Negotiation under extreme pressure. Negotiation Journal, 18(4), 331-343.

Fuselier, D. (1999). Placing the Stockholm Syndrome in perspective. FBI Law Enforcement Bulletin, July, 68(7), 22-25.

Halliday, M.A.K. (1994). An introduction to functional grammar. 2nd edition. London: Edward Arnold.

Lanceley, F. J. (1999). On-scene guide for crisis negotiators. Boca Raton: CRC Press.

McMains, M. J. \& W. C. Mullins. (2001). 2nd Edition. Crisis negotiations: Managing critical incidents and hostage situations in law enforcement and corrections. Cincinnati: Anderson Pub. Co.

Noesner, G. W. (1999). Negotiation concepts for commanders. FBI Law Enforcement Bulletin, January, 68(1), 6-14.

Noesner, G. W. \& Webster, M. (1997). Crisis intervention: Using active listening skills in negotiations. FBI Law Enforcement Bulletin, August, 66(8), A pdf file is available at the following website: www.fbi.gov/publications/leb/1997/aug974.htm

O’Reilly, J. (2003). Personal Correspondence. Sydney, Australia.

Psathas, G. (1995). Conversation Analysis: The study of talk-in-interaction. Qualitative Research Methods Series, No. 35. London: Sage Publications.

Rogan, R. G. \& M. R. Hammer, C. Van Zandt. (1997). Dynamic processes of crisis negotiation. Westport, Connecticut: Praeger.

Romano, S. J. (1998). Third party intermediaries for crisis negotiations. FBI Law Enforcement Bulletin, October, 67(10), 20-24.

Royce, T. D. (2005). The negotiator and the bomber: Analyzing the critical role of active listening in crisis negotiations. Negotiation Journal, January, 21(1), 5-27. 
Schlossberg, H. (1979). Hostage negotiations school. Austin, TX: Texas Department of Public Safety.

Wind, B. (1995). A guide to crisis negotiations. FBI Law Enforcement Bulletin, October, 64(10), 7-12. 